\title{
Antibiotic Treatment of Experimental Endocarditis Due to Methicillin-Resistant Staphylococcus epidermidis
}

\author{
José M. Entenza, Ursula Fluckiger, Michel P. Glauser, \\ and Philippe Moreillon
}

Division of Infectious Diseases. Department of Internal Medicine. Centre Hospitalier Universitaire Vaudois, Lausanne, Switzerland

\begin{abstract}
The natural history and treatment of experimental endocarditis due to heterogeneous and homogeneous methicillin-resistant Staphylococcus epidermidis was investigated. Amoxicillin/ clavulanate or vancomycin were administered for 3 days via a computerized pump to mimic human drug kinetics in animals. After challenge with the minimum inoculum producing $90 \%$ of infections ( $\mathrm{ID}_{90}$ ), bacteria in the vegetations grew logarithmically for $16 \mathrm{~h}$. Then, bacterial densities stabilized (at $\sim 10^{8} \mathrm{cfu} / \mathrm{g}$ ) and growth rates sharply declined. Both regimens cured $\geqslant 60 \%$ of endocarditis (due to heterogeneous or homogeneous bacteria) when started 12-16 h after infection, although the bacterial densities in the vegetations had increased by 20 times in between. In contrast, treatment started after $24 \mathrm{~h}$ failed in most animals, while bacterial densities had not increased any more. Thus, while both regimens were equivalent, the therapeutic outcome was best predicted by growth rates in the vegetations, not by bacterial densities. These observations highlight the importance of phenotypic tolerance developing in vivo.
\end{abstract}

In the early 1940s, the introduction of penicillin in medicine was rapidly followed by the emergence of penicillinaseproducing penicillin-resistant staphylococci, posing the first major challenge to the then-nascent era of antimicrobial chemotherapy [1]. Twenty years later this scenario was partially repeated when it appeared that antibiotic pressure with the newly available penicillinase-stable methicillin selected for a new, so-called intrinsic type of resistance to $\beta$-lactams [2]. Intrinsic resistance to methicillin was not due to penicillinase production but appeared to require the production of a new, unique, penicillin-binding protein (PBP) with low $\beta$ lactam affinity (called PBP $2 A$ or $2^{\prime}$ ) in addition to the normal set of staphylococcal PBPs [3, 4]. PBP 2A is also considered to be responsible for cross-resistance to most other $\beta$-lactam antibiotics (for review see [5]).

Today, methicillin resistance is genuinely ubiquitous in hospital isolates of staphylococci. In Switzerland, for instance, $40 \%-60 \%$ of hospital isolates of Staphylococcus epidermidis are resistant to methicillin [6] (unpublished data). Although less common, the frequency of methicillin-resistant Staphylococcus aureus varies from 3\% in our hospital [7] to $20 \%$ in other hospitals of the country (Auckenthaler R, personal communication). In the United States, up to $40 \%$ of $S$. aureus isolates are resistant to methicillin in certain insti-

Received 8 November 1993: revised 23 February 1994.

Presented in part: $32 \mathrm{nd}$ Interscience Conference on Antimicrobial Agents and Chemotherapy. October 1992, Anaheim, California (abstract 1458).

Grant support: Swiss National Foundation for Research (32-2-7777).

Reprints or correspondence: Prof. Michel P. Glauser, Div. of Infectious Diseases, Dept. of Internal Medicine, Centre Hospitalier Universitaire Vaudois, $\mathrm{CH}-101 \mathrm{l}$. Lausanne, Switzerland

The Journal of Infectious Diseases 1994;170:100-9

(c) 1994 by The University of Chicago. All rights reserved. $0022-1899 / 94 / 7001-0015 \$ 01.00$ tutions [8]. In addition, most of these organisms are resistant to a number of other drugs $[5,9]$, posing a serious challenge to antimicrobial therapy.

The only nonexperimental antibiotic to which methicillinresistant staphylococci are still considered uniformly sensitive is vancomycin, which is potentially toxic and can be given only parenterally (see [5]). However, staphylococci may be on the verge of becoming totally resistant to any available antibiotics, since it has been shown in the laboratory that vancomycin resistance could be transferred to $S$. aureus from vancomycin-resistant enterococci [10]. Transfer of vancomycin resistance into methicillin-resistant staphylococci would have major consequences for public health. To decrease the risk of this occurrence, it is necessary both to interfere with the spread of methicillin-resistant staphylococci and to develop alternative, nonglycopeptide antimicrobial agents to prevent selection of glycopeptide resistance in such organisms.

The purpose of the present study was to investigate the efficacy of the nonglycopeptide combination amoxicillin/ clavulanate in the treatment of experimental endocarditis due to methicillin-resistant $S$. epidermidis (MRSE). The rationale of the experiments was based on the dual observations that amoxicillin/clavulanate could cure experimental endocarditis due to methicillin-resistant $S$. aureus (MRSA) [11, 12] (presumably because of the relatively good aftinity of amoxicillin for PBP 2A [12]) and that a similar PBP 2A mediates high level of methicillin resistance in both MRSA and MRSE [13-15]. In addition, since the course of experimental endocarditis due to $S$. epidermidis appeared to be more indolent and resulted in less mortality than with $S$. aureus, we investigated the therapeutic outcome of treatment started either early or relatively late after the induction of infection in animals. 
Table 1. Principal characteristics of the methicillin-resistant $S$. epidermidis (MRSE) isolates.

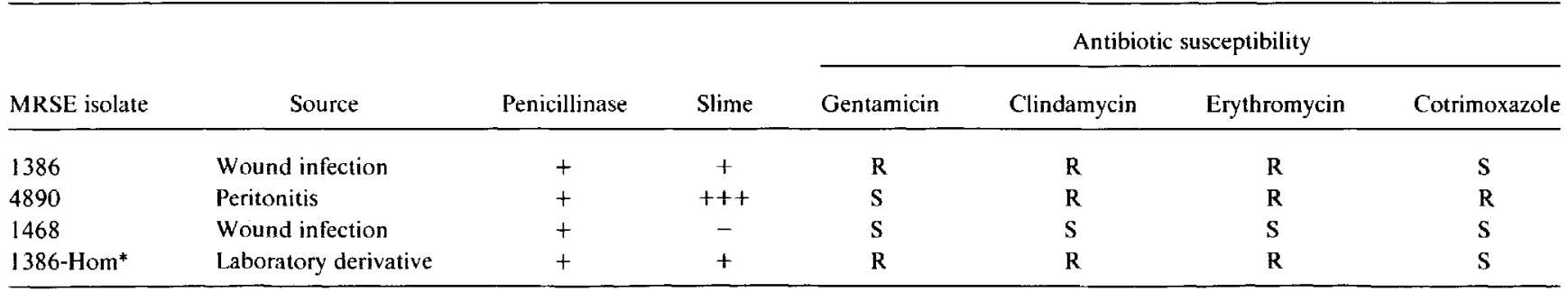

NOTE. Penicillinase and slime production were measured by semiquantitative methods [17, 18]. S, susceptible; $R$, resistant as determined by standard disk diffusion method [19].

* Homogeneous.

\section{Materials and Methods}

\section{Microbiologic Methods}

Microorganisms and growth conditions. The principal characteristics of the four strains of MRSE used in these experiments are summarized in table 1. Strains MRSE 1386, 4890, and 1468 were clinical isolates recovered from distinct geographic areas and typically expressing so-called heterogeneous resistance to methicillin. Strain MRSE 1386-Hom was a homogeneously methicillin-resistant derivative of strain MRSE 1386, which had been selected by serial passage of the parent strain on methicillin-containing medium as described [16]. Strain 1386-Hom was stable, as it appeared to retain its homogeneously resistant phenotype for up to 60 generations in the absence of antibiotic pressure in vitro (see [16]). All 4 strains produced penicillinase as assessed both by a positive nitrocefin test and by inactivation of amoxicillin using a described method [17]. The production of slime was assessed by a semiquantitative method [18] and antibiotic susceptibilities were determined by standard disk diffusion test [19].

Unless otherwise stated, the bacteria were grown at $35^{\circ} \mathrm{C}$ in Mueller-Hinton broth (MHB; Difco, Detroit) supplemented with $2 \% \mathrm{NaCl}$ or on Columbia agar (C agar; Becton Dickinson, Cockeysville, MD) supplemented with $4 \% \mathrm{NaCl}$. Stocks were kept at $-70^{\circ} \mathrm{C}$ in MHB supplemented with $10 \%$ glycerol.

Antibiotics. Amoxicillin and clavulanate (either individually or in a $5: 1$ [wt/wt] ratio) and flucloxacillin were obtained from Beecham Laboratories (Brockham Park, UK) and vancomycin from Eli Lilly (Indianapolis).

Antibiotic susceptibility. MICs of several antibiotics were determined by a standard macrobroth method [20] in MHB supplemented with calcium and $2 \% \mathrm{NaCl}$ (as recommended for susceptibility testing of MRSA [21]) using $10^{5} \mathrm{cfu} / \mathrm{mL}$ as an inoculum. The MIC was defined as the lowest drug concentration inhibiting visible bacterial growth after $24 \mathrm{~h}$ of incubation at $35^{\circ} \mathrm{C}$. For MIC determinations of the combination of amoxicillin/ clavulanate, the drugs were used in a ratio of $2: 1(\mathrm{wt} / \mathrm{wt})$.

Population analysis profle. The phenotypic expression of methicillin resistance in vitro was determined as described [12]. In brief, serial dilutions of MRSE cultures (in MHB supplemented with $2 \% \mathrm{NaCl}$ ) in the late exponential phase of growth were inoculated onto $\mathrm{C}$ agar plates supplemented with $4 \% \mathrm{NaCl}$ and containing increasing concentrations of either methicillin or amoxicillin/clavulanate. Clavulanate was used at a fixed con- centration of $5 \mathrm{mg} / \mathrm{L}$. Large $\left(>10^{8} \mathrm{cfu}\right)$ and smaller $\left(10^{6}, 10^{4}\right.$, and $10^{2} \mathrm{cfu}$ ) bacterial numbers were plated. The numbers of colonies growing on the antibiotic-containing plates were determined after $48-72 \mathrm{~h}$ of incubation at $35^{\circ} \mathrm{C}$. Curves of the population analysis profile were generated by plotting the numbers of colonies growing on the plates against the concentrations of antibiotic in the plates.

In vitro time-kill curves. Series of flasks containing $20 \mathrm{~mL}$ of fresh MHB (prewarmed at $35^{\circ} \mathrm{C}$ ) supplemented with $2 \% \mathrm{NaCl}$ were inoculated with $1 / 100(\mathrm{vol} / \mathrm{vol}$ ) of an overnight culture of bacteria (grown in the same medium) and incubated with aeration in a shaking incubator (at $120 \mathrm{rpm}$ ). Antibiotics (either amoxicillin/clavulanate or vancomycin) were added at different times during the logarithmic or the stationary phase of growth, and bacterial survival was followed by plating dilutions of the cultures onto $C$ agar plates supplemented with 2000 units of penicillinase $/ \mathrm{mL}$ (Bacto-Penase concentrate; Difco). Final concentrations of antibiotics were chosen to mimic the peak serum levels obtained in humans (or rats) during intravenous (iv) therapy: 90 and $20 \mathrm{mg} / \mathrm{L}$ for amoxicillin and clavulanate, respectively, and $40 \mathrm{mg} / \mathrm{L}$ for vancomycin. All measurements were made in triplicate.

\section{Animal Experiments}

Production of endocarditis and installation of an infusion pump device. Sterile aortic vegetations were produced in female $W$ istar rats (180-200 g) as described [22]. In brief, the animals were anesthetized and a polyethylene catheter (Guerbet Biomédical, Louvres, France) was inserted via the right carotid artery across the aortic valve. The catheter was secured with a silk ligature and left in place for the remainder of the experiment. At the same time, an iv line consisting of a sterile Silastic catheter (inside and outside diameters, 0.02 and $0.037 \mathrm{~mm}$, respectively; Dow Corning, Midland, MI) was inserted via the jugular vein in to the superior vena cava for the delivery of the antibiotics. The distal portion of the catheter was brought to the skin of the interscapular region and connected to a programmable infusion pump device (Pump 44; Harvard Apparatus, South Natick, MA) through a swivel that permitted the animals to move in an unrestrained fashion in their cage. Bacterial endocarditis was induced $24 \mathrm{~h}$ after catheterization by iv challenge of the animals with various inocula.

Natural history of experimental endocarditis due to MRSE. 
To determine the minimum size of bacterial inoculum producing endocarditis in $90 \%$ of the rats $\left(\mathrm{ID}_{90}\right)$, groups of rats $(8-10$ animals) were challenged through a tail vein with $0.5 \mathrm{~mL}$ of saline containing $10^{3}-10^{6} \mathrm{cfu}$ of each test organism. The animals were killed $24 \mathrm{~h}$ after inoculation. One milliliter of blood was drawn and plated for quantitative blood cultures. The aortic vegetations were sterilely dissected, weighed, homogenized in I $\mathrm{mL}$ of saline, and serially diluted before plating for quantitative cultures. The technique permitted the detection of $\geqslant 2 \log _{\mathrm{I}} \mathrm{cfu} /$ $\mathrm{g}$ of tissue. The spleens were also processed for quantitative cultures as described. The numbers of colonies growing on the plates were determined after incubation at $35^{\circ} \mathrm{C}$ for $48 \mathrm{~h}$.

To determine the kinetics of bacterial growth in the animats, groups of rats challenged with either the $\mathrm{ID}_{90}$ or $10 \times \mathrm{ID}_{90}$ were killed at various times after iv bacterial challenge and the blood, vegetations, and spleens were cultured as described.

Treatment of experimental endocarditis. Groups of rats challenged with either the $\mathrm{ID}_{90}$ or $10 \times \mathrm{ID}_{90}$ of various strains of MRSE were treated with either flucloxacillin, amoxicillin/ clavulanate, or vancomycin (flucloxacillin was used instead of methicillin because the latter antibiotic is no longer used in the clinic). To simulate in animals the human serum kinetics during standard iv treatment (i.e., $1.2 \mathrm{~g}$ four times daily for amoxicillin/ clavulanate and $1.0 \mathrm{~g}$ twice daily for vancomycin), these drugs were delivered to the animals at changing flow rates using a programmable pump device. This required the injection of $164.4 \mathrm{mg}$ of amoxicillin/clavulanate (5:1 [wt/wt] ratio)/kg every $6 \mathrm{~h}$ (beginning with a bolus of $80.0 \mathrm{mg} / \mathrm{kg}$ followed by the progressively decreasing infusion of the remaining $84.4 \mathrm{mg} / \mathrm{kg}$ ) and $23.2 \mathrm{mg}$ of vancomycin $/ \mathrm{kg}$ delivered at changing flow rates over a $12-\mathrm{h}$ period. Flucloxacillin $(200 \mathrm{mg} / \mathrm{kg}$ every $5 \mathrm{~h}$ ) was administered subcutaneously (sc).

Therapy was started at various times after bacterial inoculation (see Results) and lasted for 3 days. The rats were sacrificed $12 \mathrm{~h}$ after the last antibiotic dose (when drug was no longer detected in the blood), and endocarditis was evaluated quantitatively as described. Each therapeutic experiment was matched against a control group of rats killed at the initiation of therapy.

Determination of serum antibiotic concentrations. Serum levels of antibiotics were determined in both uninfected and infected rats (groups of 3-6 animals) at various time points during and after antibiotic administration. Antibiotic concentrations were measured by an agar diffusion bioassay using Bacillus subti- lis ATCC 6633 for amoxicillin, flucloxacillin, and vancomycin and Klebsiella pneumoniae ATCC 29665 plus $60 \mathrm{mg}$ of penicillin/L for clavulanate [23]. For standard curves, antibiotics were diluted in pooled rat serum.

Expression of antibiotic resistance in vivo. To evaluate the number of highly methicillin-resistant organisms present on the valves at the onset of therapy, quantitative cultures of vegetations from control animals were plated on agar containing 25 $\mathrm{mg}$ of methicillin/L in parallel with cultures on plain medium. In addition, the vegetations of animals treated with amoxicillin/ clavulanate were plated simultaneously on plain and antibioticcontaining agar plates (containing $5 \mathrm{mg}$ of clavulanate/L plus either 25 or $100 \mathrm{mg}$ of amoxicillin) to detect the possible emergence of antibiotic-resistant organisms in vivo. This screening was not done in vancomycin-treated animals.

Statistical analysis. The $\chi^{2}$ test with Yates's correction was used to compare the incidence of valvular and spleen infections.

\section{Results}

\section{Antibiotic Determinations}

Antibiotic susceptibility. Table 2 shows the MICs of several antibiotics for the 4 isolates of MRSE plus 1 clinical isolate of methicillin-sensitive $S$. epidermidis used as a control. Since most methicillin-resistant staphylococci express a so-called heterogeneous type of resistance to $\beta$-lactams, we also determined the population analysis profile of each of the test organisms on $\beta$-lactam-containing plates (figure 1). All three clinical isolates (MRSE 1386, 4890, and 1468) typically expressed heterogeneous resistance to methicillin (as exemplified for strain MRSE 1386 in figure 1A) and contained subpopulations of bacteria able to grow on plates containing 500-1000 mg of methicillin/L. Importantly, the profile of methicillin resistance was not altered when clavulanate ( $5 \mathrm{mg} / \mathrm{L}$ ) was added to the medium. In contrast, no bacteria could grow on plates containing $>25 \mathrm{mg}$ of amoxicillin $/ \mathrm{L}$ in the presence of clavulanate $(5 \mathrm{mg} / \mathrm{L})$. Figure $1 \mathrm{~B}$ shows that serial passage of the parent strain MRSE 1386 on methicillin resulted in a derivative (MRSE 1386Hom) that was homogeneously resistant to methicillin, that

Table 2. Phenotype of methicillin resistance and MICs of methicillin-resistant S. epidermidis (MRSE) test organisms to various antibiotics.

\begin{tabular}{|c|c|c|c|c|c|c|c|}
\hline \multirow[b]{2}{*}{ MRSE isolate } & \multirow[b]{2}{*}{ Phenotype } & \multicolumn{6}{|c|}{$\mathrm{MIC}(\mathrm{mg} / \mathrm{L})$} \\
\hline & & Methicillin & Flucloxacillin & Amoxicillin & Clavulanate & Amoxicillin/clavulanate & Vancomycin \\
\hline 4890 & Het & 128 & 32 & 32 & $>128$ & 4 & 2 \\
\hline 1468 & Het & $>128$ & 64 & 64 & $>128$ & 4 & 2 \\
\hline 1386 & Hom & $>128$ & $>128$ & $>64$ & $>128$ & 8 & 4 \\
\hline
\end{tabular}

NOTE. Het, heterogeneously resistant; Hom, homogeneously resistant to methicillin: ND, not determined.

* Clinical isolate of methicillin-susceptible $(S) S$ epidermidis (producing penicitinase) used as control. 
Figure 1. Population analysis profile of heterogeneously methicillin-resistant $S$. epidermidis isolate 1386 (A) and its homogeneously resistant derivative 1386-Hom (B). Bacteria (>10 $\left.0^{8} \mathrm{cfu}\right)$ were plated on Columbia agar supplemented with $4 \% \mathrm{NaCl}$ and twofold serial dilutions of either methicillin ( $\square$ ), amoxicillin $(\mathrm{O})$, methicillin/clavulanate (ם), or amoxicillin/clavulanate (๑). Clavulanate was used at fixed concentration of $5 \mathrm{mg} / \mathrm{L}$. Heterogeneous profile of 1386-Hom on amoxicillin alone was most likely due to residual penicillinase secretion by bacteria.
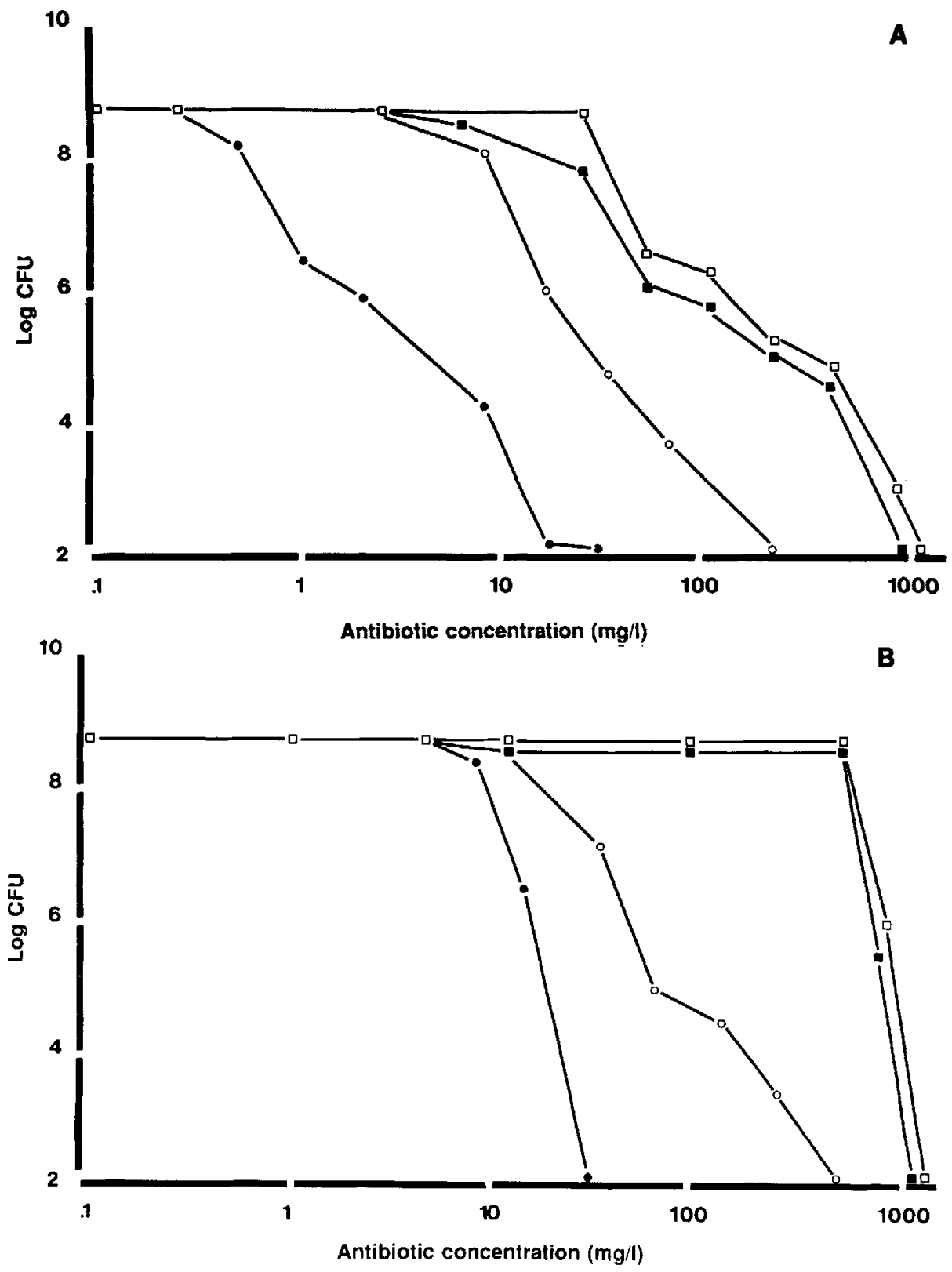

is, all colony-forming units in the bacterial population expressed high-level resistance to the drug. The homogeneous derivative was also homogeneously susceptible to amoxicillin in the presence of clavulanate. In contrast, when plated on amoxicillin alone, some heterogenicity was observed. This was most likely because of production of penicillinase by the bacteria, which resulted in degradation of amoxicillin in situ.

Antibiotic serum levels. After one injection of flucloxacillin $(200 \mathrm{mg} / \mathrm{kg} \mathrm{sc})$, both the peak serum levels $(124.3 \mathrm{mg} / \mathrm{L})$ and the half-life of the drug $(0.5 \mathrm{~h})$ were comparable to those observed during iv therapy in humans $(125.2 \mathrm{mg} / \mathrm{L}$ and 0.5 $h$, respectively [24]). After continuous infusion, serum levels of amoxicillin, clavulanate, and vancomycin closely fol- lowed the human serum kinetics produced by iv injections of $1 \mathrm{~g}$ of amoxicillin, $0.2 \mathrm{~g}$ of clavulanate, and $1 \mathrm{~g}$ of vancomycin $[25,26]$. Serum levels in rats at $30 \mathrm{~min}$ and 2,4 , and $6 \mathrm{~h}$ were as follows: amoxicillin, $89.4 \pm 23,13.9 \pm 1.4,3.5 \pm$ 2.0 , and $1.2 \pm 0.9 \mathrm{mg} / \mathrm{L}$; clavulanate, $13.4 \pm 5.0,2.1 \pm 0.5$, $1.1 \pm 0.4$, and $0.3 \pm 0.1 \mathrm{mg} / \mathrm{L}$; and vancomycin, $40.5 \pm 6.0$, $30.0 \pm 4.9,21.5 \pm 8.9$, and $15.4 \pm 2.0 \mathrm{mg} / \mathrm{L}$ (and $3.7 \pm 2.8$ $\mathrm{mg} / \mathrm{L}$ at $12 \mathrm{~h}$ ).

\section{Animal Studies}

Natural history of experimental MRSE endocarditis. The minimum bacterial inoculum producing endocarditis in $90 \%$ of the rats $\left(\mathrm{ID}_{90}\right)$ was $10^{5}$ cfu for all 4 strains. After challenge 


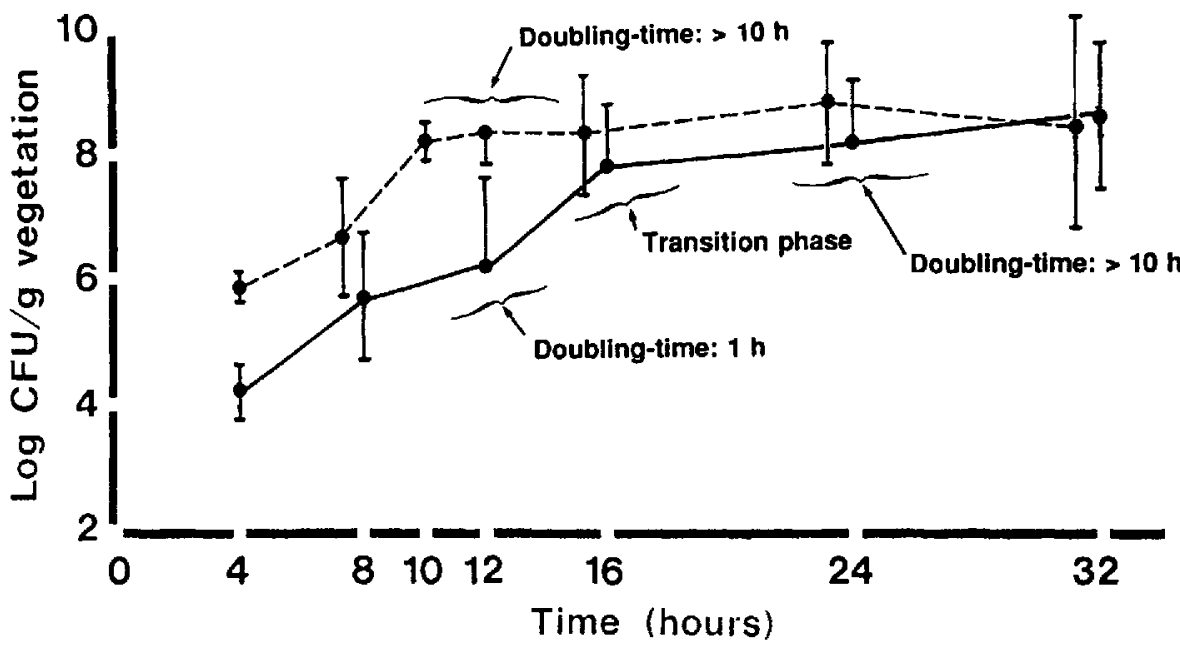

Figure 2. Natural course of experimental endocarditis due to methicillinresistant $S$. epidermidis (MRSE) isolate 1386 in rats challenged with either $10^{5}$ cfu (ID 90 , solid line) or $10^{6} \mathrm{cfu}(10 \times$ $\mathrm{ID}_{90}$, dashed line). Each point represents mean $\pm S D$ of 7-25 animals. Doubling times were derived from the growth curves on the graph. After challenge with $10 \times \mathrm{ID}_{90}$, bacterial growth in vegetations stopped $\sim 6$ h earlier than after $\mathrm{ID}_{90}$. with such an inoculum (solid line, figure 2), bacteria in the vegetations first entered a phase of rapid division (generation time, $\sim 1 \mathrm{~h}$ ) that lasted until bacterial densities on the valves had reached $\sim 10^{8} \mathrm{cfu} / \mathrm{g}$ of vegetation, at $\sim 16$ h after bacterial challenge. At that time, the generation time progressively decreased (by about 10 times) and bacterial densities reached a plateau. The proportion of animals with positive blood cultures increased with the severity of valvular infection (from $36 \%$ to $53 \%$ and $72 \%$ at 12,16 , and $24 \mathrm{~h}$, respectively, for all 3 clinical isolates). In contrast, all the spleen cultures were positive from the beginning, but total bacterial numbers and densities in this organ remained relatively stable over the course of the disease $\left(\log _{10} \mathrm{cfu} / \mathrm{g}\right.$ of spleen, 2.8-3.4).

After challenge with $10^{6} \mathrm{cfu}$ (i.e., $10 \times \mathrm{ID}_{90}$; dashed line, figure 2), the course of experimental endocarditis was roughly parallel to that following injection of the $\mathrm{ID}_{90}$ but the growth curve was globally shifted to the left.

Expression of methicillin resistance in vivo. Expression of methicillin resistance in the vegetations of untreated rats did not vary over time. For the 3 heterogeneously resistant clinical isolates, the frequency of bacterial subpopulations able to grow on plates containing $25 \mathrm{mg}$ of methicillin/L was $2-6 \times$ $10^{-5}$ during the whole course of infection. Similar control experiments with the derivative MRSE 1386-Hom showed that the homogenous phenotype also persisted in vivo, as $100 \%$ of the bacteria recovered from the vegetations of untreated animals grew on plates containing $100 \mathrm{mg}$ of methicillin/L.

Therapeutic experiments. The rather indolent course of MRSE endocarditis allowed us to investigate the efficacy of antibiotherapy started either early ( 12 or $16 \mathrm{~h}$ after bacterial challenge) or relatively late ( $24 \mathrm{~h}$ after inoculation). This type of late treatment was not possible in former experiments done with MRSA isolates [11, 12] because the more aggressive course of $S$. aureus endocarditis resulted in the premature deaths of many of the animals.
Figure 3 depicts the therapeutic efficacy of various antibiotic regimens against experimental endocarditis after challenge with the ID 90 of MRSE 1386, MRSE 4890, and MRSE 1468. According to the experimental design, antibiotic treatment was started either 12,16 , or $24 \mathrm{~h}$ after bacterial challenge and lasted for 3 days. Animals were always sacrificed $12 \mathrm{~h}$ after the last antibiotic dose. As expected, treatment with flucloxacillin failed against all three organisms. In contrast, both amoxicillin/clavulanate and vancomycin successfully treated most of the infected rats when started 12 or $16 \mathrm{~h}$ after bacterial challenge. However, the therapeutic efficacy of both regimens tended to decrease with delayed onset of treatment and clearly failed (at least for MRSE 1386 and MRSE 4890) when started $24 \mathrm{~h}$ after bacterial challenge.

Analysis of the vegetations showed that this drop in effectiveness did not correlate well with the bacterial densities in the valvular lesions but did correlate with the rate of bacterial growth in situ (figure 2,3 ). Indeed, treatment started at either 12 or $16 \mathrm{~h}$ resulted in practically similar cure rates despite the fact that bacterial densities in the vegetations had increased by 20 times between those time points. During this time, bacterial growth was relatively fast (figures 2,3 ). In contrast, the cure rates decreased between 16 and $24 \mathrm{~h}$, while the rate of bacterial growth in situ had come to a virtual halt (doubling time, $\geqslant 10 \mathrm{~h}$ ) and bacterial densities in the vegetations did not increase any more. Treatment failures were not due to organisms resistant to amoxicillin/clavulanate, as bacteria recovered from the infected valves and directly plated on antibiotic-containing agar had retained the sensitivity of the original strain (data not shown). Thus, in the present experiments, the therapeutic efficacy of amoxicillin/ clavulanate and vancomycin was best predicted by the rate of bacterial growth in situ, not by the bacterial densities in the vegetations.

To investigate how therapy might be affected by larger inocula, groups of rats were inoculated with $10 \times \operatorname{ID}_{90}\left(10^{6}\right.$ cfu) of strain MRSE 1386 and treated as described. As 

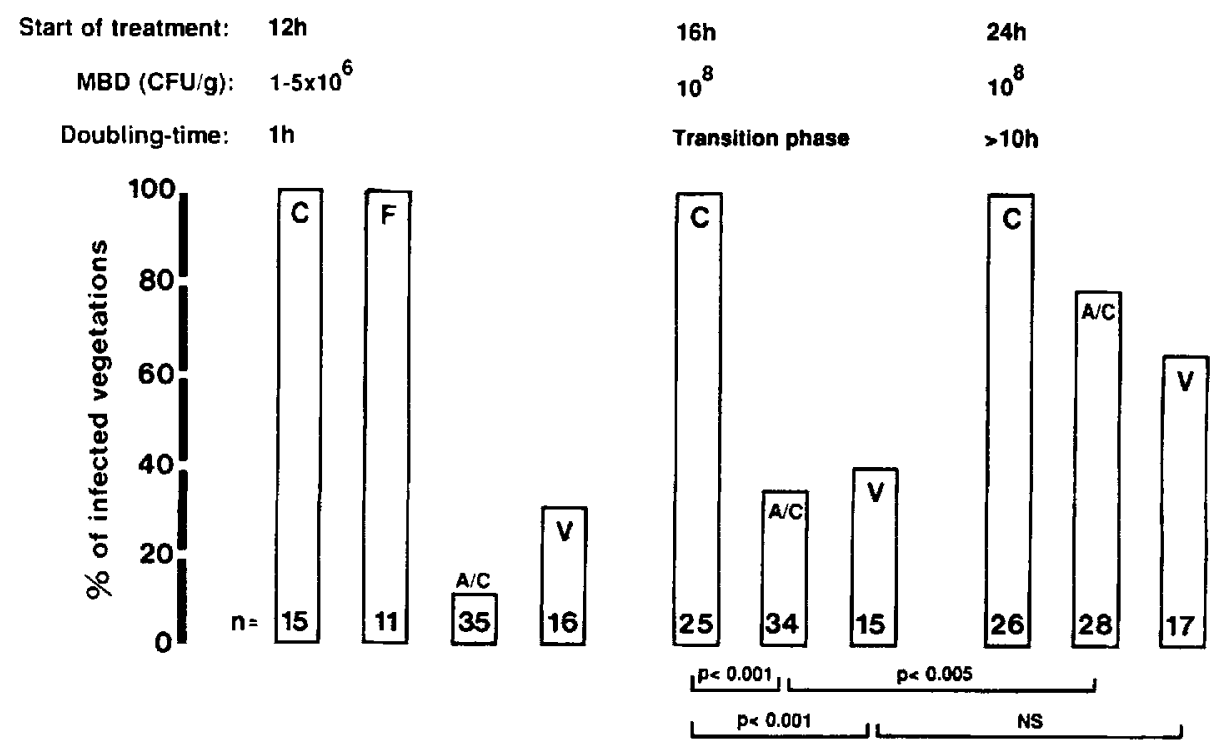

Figure 3. Antibiotic treatment of experimental endocarditis in rats infected with $10^{5} \mathrm{cfu}\left(\mathrm{ID}_{90}\right)$ of methicillin-resistant $S$. epidermidis isolates 1386 (top), 4890 (center), and 1468 (bottom). $\mathrm{MBD}$, median bacterial densities. Vegetations were considered sterile when no growth occurred from cultures of undiluted homogenates. Numbers of animals in each group are indicated at bottom of columns. $C$, control; $F$, flucloxacillin; $\mathrm{A} / \mathrm{C}$, amoxicillin/clavulanate; $V$, vancomycin; NS, not significant.
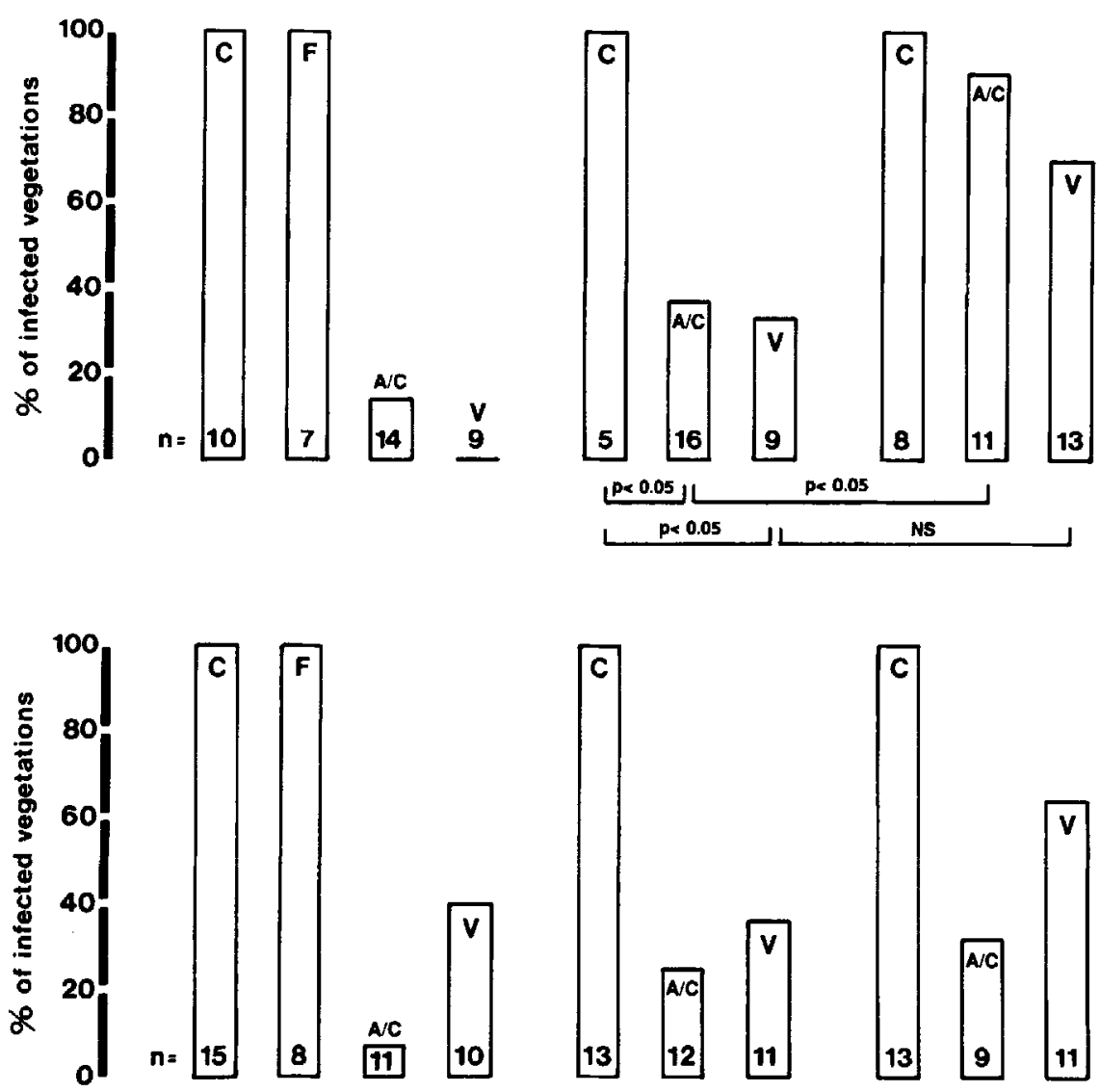

LP 0.05

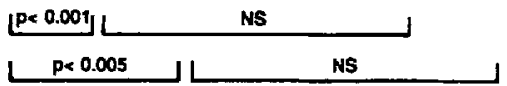


shown in figure 2 (dashed line), after challenge with this larger inoculum, the bacterial densities in the vegetations attained the plateau $\left(\sim 10^{8} \mathrm{cfu} / \mathrm{g}\right)$ sooner than after inoculation with the $\mathrm{ID}_{90}$ (presumably because the valves had been originally colonized with more bacteria after this larger inoculum, as in experimental streptococcal endocarditis [27]) and bacterial growth in situ already came to a halt $10 \mathrm{~h}$ after bacterial challenge (instead of $>16 \mathrm{~h}$ after challenge with the $\mathrm{ID}_{90}$ ). Therefore, 3 days of treatment with either amoxicillin/ clavulanate or vancomycin failed, even when started as soon as $12 \mathrm{~h}$ after infection (figure 4).

Experiments with the homogeneously resistant derivative MRSE 1386-Hom. Since only 2-6 $\times 10^{-5}$ of the heterogeneously resistant bacteria expressed high-level methicillin resistance at the onset of therapy, the question arose as to whether the efficacy of amoxicillin/clavulanate was exaggerated as a result of relatively few highly resistant bacteria in the vegetations at the onset of therapy. Therefore, the experiments described above were repeated in rats challenged with $10^{5}$ cfu $\left(1 D_{90}\right)$ of the homogeneously resistant derivative MRSE 1386-Hom. As mentioned in Materials and Methods, the homogeneous character of this organism was stable in vitro. This also appeared to be true in vivo, as the whole bacterial population in the vegetations expressed high-level methicillin resistance at the beginning of treatment. Despite this, amoxicillin/clavulanate started either 12 or $16 \mathrm{~h}$ after infection successfully treated $84 \%$ and $78 \%$ of the animals, respectively $\left(P<10^{-4}\right.$ and $10^{-3}$ compared with controls, respectively). Consequently, it appeared that the efficacy of amoxicillin/clavulanate had not been overestimated by the heterogeneous nature of the clinical isolates.

Survival of bacteria in the spleens. Spleen cultures tended

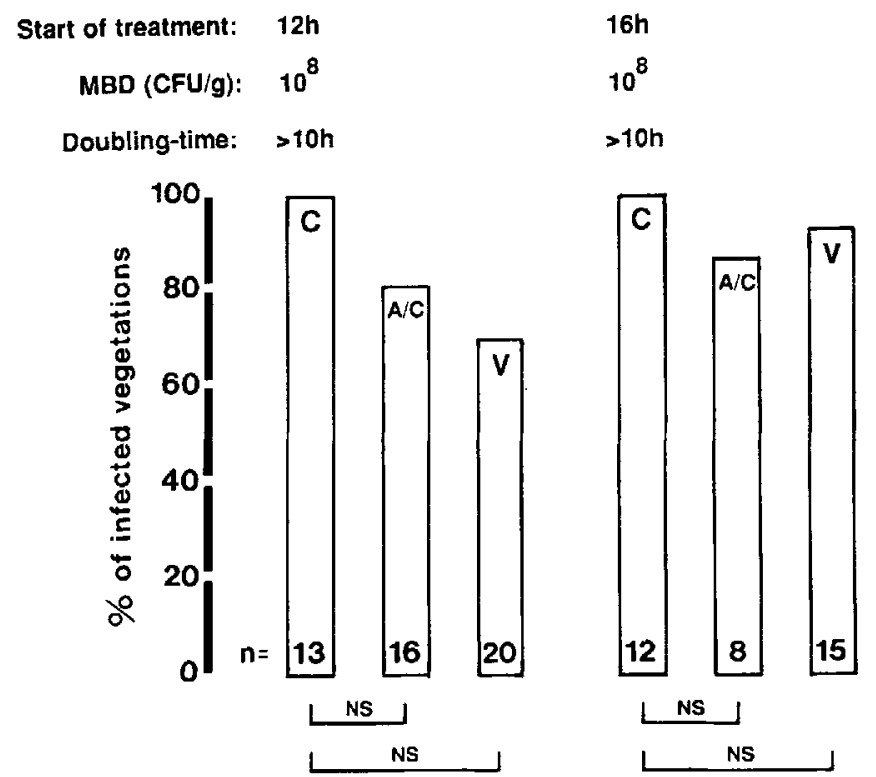

Figure 4. Antibiotic treatment of experimental endocarditis in rats infected with $10^{6} \mathrm{cfu}\left(10 \times 1 \mathrm{D}_{90}\right)$ of methicillin-resistant $S$. epidermidis isolate 1386. See figure 3 legend for details. to be more frequently sterile in rats treated with amoxicillin/ clavulanate than in rats treated with vancomycin. The trend was observed at each treatment time and for both inoculum sizes (table 3). However, the differences between groups treated with amoxicillin/clavulanate and vancomycin were statistically significant only when therapy was started at either 12 or $16 \mathrm{~h}$ after challenge with the $\mathrm{ID}_{90}$ or at $12 \mathrm{~h}$ after challenge with $10 \times \mathrm{ID}_{90}$ (table 3 ).

In vitro time-kill curves. Since cardiac vegetations are considered devoid of host defense mechanisms [28, 29], the therapeutic results described above are likely to result almost exclusively from antibiotic-induced bacterial killing in the vegetations. Thus, it must be possible to mirror the results obtained in vivo in time-kill curves determined in vitro. The results of such an experiment (using strain MRSE 1386) are shown in figure 5. During the logarithmic phase of growth, both amoxicillin/clavulanate and vancomycin (used at concentrations mimicking the peak serum levels in vivo) were highly bactericidal over a large range of bacterial densities, which encompassed several orders of magnitude. In contrast, as bacterial growth came to a halt, antibiotic-induced killing abruptly decreased while bacterial densities in the medium remained stable (between $10^{8}$ and $10^{9} \mathrm{cfu} / \mathrm{mL}$ ). Thus, as was the case in vivo, antibiotic-induced killing in vitro depended essentially on the rate of bacterial growth, not on bacterial densities in the medium. Similar results were also observed with the 2 other clinical isolates of MRSE. Note that the late regrowth of bacteria in vancomycin-treated cultures (figure $5 \mathrm{~B}$ ) was not due to the emergence of resistant organisms but to the progressive loss of efficiency of the drug, as determined using an agar diffusion bioassay. Indeed, after $48 \mathrm{~h}$ of incubation, the antibiotic activity of vancomycin in the culture supernatants had decreased by 10 times, whereas that of amoxicillin/clavulanate had decreased only by 2 times.

\section{Discussion}

In the present experiments, amoxicillin/clavulanate was as effective as vancomycin against experimental endocarditis

Table 3. Number of rats with positive spleen cultures in antibiotic-treated animals.

\begin{tabular}{lcccc} 
& \multicolumn{3}{c}{ No. spleens culture-positive/total (\%) } & \\
\cline { 2 - 4 } $\begin{array}{l}\text { Inoculum, time of } \\
\text { treatment onset }\end{array}$ & Flucloxacillin & $\begin{array}{c}\text { Amoxicillin/ } \\
\text { clavulanate }\end{array}$ & Vancomycin & $P^{*}$ \\
\hline $\mathrm{ID}_{90}\left(10^{5} \mathrm{cfu}\right)$ & & & & \\
$12 \mathrm{~h}$ & $20 / 20(100)$ & $1 / 42(2)$ & $10 / 29(34)$ & $<.001$ \\
$16 \mathrm{~h}$ & $\mathrm{ND}$ & $5 / 44(11)$ & $11 / 29(38)$ & $<.05$ \\
$24 \mathrm{~h}$ & $\mathrm{ND}$ & $13 / 33(39)$ & $15 / 30(50)$ & $\mathrm{NS}$ \\
$10 \times\left[\mathrm{D}_{90}\left(10^{6} \mathrm{cfu}\right)\right.$ & $\mathrm{ND}$ & $0 / 9$ & $7 / 12(58)$ & $<.05$ \\
$12 \mathrm{~h}$ & $\mathrm{ND}$ & $1 / 5(20)$ & $5 / 8(62)$ & $\mathrm{NS}$ \\
$16 \mathrm{~h}$ & & & &
\end{tabular}

NOTE. ND, not determined.

* Amoxicillin/clavulanate vs, vancomycin. NS, not significant. 

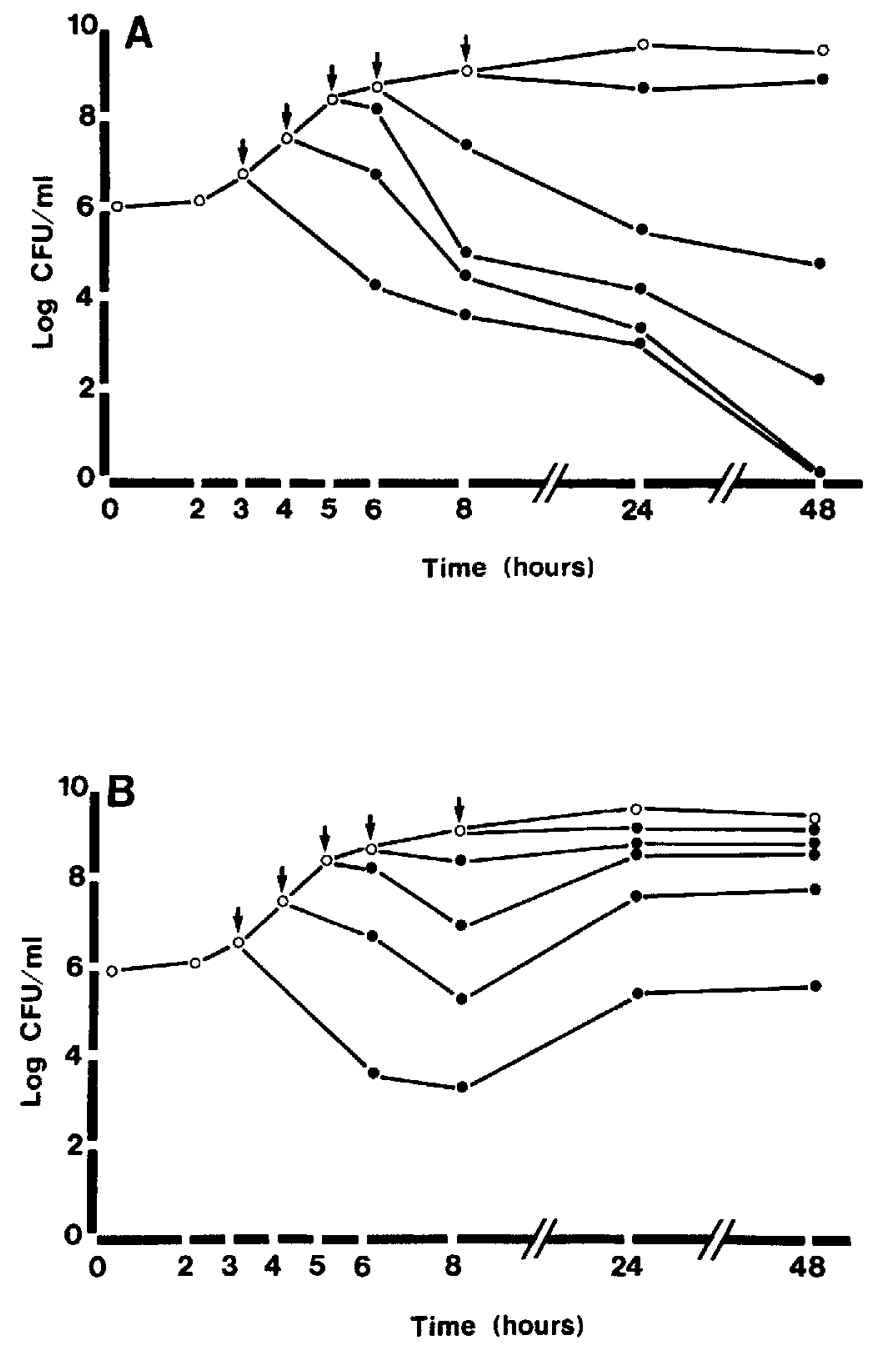

Figure 5. Time-kill curves showing bactericidal activity of amoxicillin/clavulanate (A) and vancomycin (B) against methicillin-resistant $S$. epidermidis isolate 1386 . Cultures were treated at different time points (arrows) with antibiotic concentrations reflecting peak serum level. Similar results were obtained with isolates 4890 and 1468 . $O$, untreated control cultures; $\bullet$, antibiotictreated cultures. Late regrowth of bacteria in (B) was due not to emergence of resistant organisms but to progressive loss of efficiency of drug (after 48 h of incubation, antibiotic activity of vancomycin culture supernatants, as determined by bioassay, had decreased by 10 times, whereas that of amoxicillin/clavulanate had decreased by only 2 times).

due to both heterogeneously and homogeneously resistant strains of MRSE. These results are reminiscent of those obtained in experimental endocarditis due to MRSA, where amoxicillin/clavulanate was also equivalent to vancomycin $[11,12]$. In addition, in the present experiments the spleens of animals treated with amoxicillin/clavulanate were sterile more frequently than were those of animals receiving vancomycin. While the reason(s) for this difference is speculative (e.g., do amoxicillin/clavulanate and vancomycin interfere differently with bacterial killing in the spleen?), the results underline the efficacy of the $\beta$-lactam combination in this setting.

The finding is of interest because the clustering of multiple antibiotic resistance genes in methicillin-resistant staphylococci has brought these organisms to the verge of becoming totally resistant to any available drugs. Therefore, it is essential to broaden our therapeutic armamentarium so we can treat infections due to these pathogens without selecting resistance against one of the last nonexperimental antibiotics that is still effective, that is, vancomycin.

On the basis of these results, it might be envisioned to test amoxicillin/clavulanate in patients infected with methicillinresistant staphylococci. Ideally, such a study should first be done in patients with MRSE infections, because these organisms produce much less severe diseases than do MRSA while sharing the mechanism(s) of resistance to methicillin. Several arguments suggest that such a trial might be feasible. First, in the present setting, amoxicillin/clavulanate was as effective as vancomycin in experiments in which both drugs were administered to the animals in doses that strictly mimicked the human pharmacokinetics of the antibiotics. Second, failures after experimental treatment with amoxicillin/ clavulanate did not select for more resistant bacteria in animals, thus limiting the risk of such occurrence in humans. Third, coagulase-negative staphylococci tend to produce smaller amounts of penicillinase than does $S$. aureus [30], which may be important because it has been shown that production of large quantities of penicillinase by MRSA might decrease the efficacy of amoxicillin/clavulanate in the model of experimental endocarditis [12]. Finally, S. epidermidis typically produces relatively indolent infections (in contrast to $S$. aureus), ensuring a relatively safe time in which to evaluate and readjust therapy in patients with potential treatment failures. Therefore, it might be possible to safely assess the efficacy of amoxicillin/clavulanate against MRSE infections in humans.

A second observation in the present study is the abrupt loss of efficacy of both amoxicillin/clavulanate and vancomycin as bacterial growth came to a halt in the vegetations. Decreased killing of slow-growing bacteria by cell-wall inhibitors (as well as by other antibiotics) is well known in vitro and has been referred to as phenotypic tolerance [31]. Phenotypic tolerance undoubtedly also occurs in vivo $[31,32]$ but is difficult to demonstrate in the complex biologic environment of animal models of infections. Poorly controlled factors such as host defense mechanisms, progressive alterations in the nature of the infective lesions, or alterations in the diffusion or stability of antibiotics in situ may influence the results either positively or negatively.

In this regard, experimental endocarditis is an advantageous model because cardiac vegetations are virtually devoid of cellular host defenses $[28,29]$. In addition, in the present experiments, the failure of delayed therapy (started at $24 \mathrm{~h}$ ) was not the result of major changes in the vegetation or alteration of local drug diffusion for two reasons. The 
mass of the valvular lesions did not increase between 16 and $24 \mathrm{~h}$ after infection (data not shown) and the correlation between the abrupt switch off of antibiotic-induced bacterial killing and the slowdown of bacterial growth at high bacterial densities was fully reproducible in liquid cultures in vitro, where antibiotic diffusion is not a major issue. Thus, the present experiments clearly illustrate the phenomenon of phenotypic tolerance in vivo. The results also provide a plausible explanation for previously reported treatment failures associated with high bacterial densities in the vegetations $[33,34]$. Such treatment failure (sometimes attributed to an ill-defined inoculum effect) may largely result from slow growth (i.e., a state of phenotypic tolerance) of bacteria in situ rather than from high bacterial densities per se. In the present experiments, a genuine inoculum effect was illustrated in animals challenged with large bacterial inocula ( 10 $\times \mathrm{ID}_{90}$ ): Halt in growth due to high bacterial densities in situ was attained sooner than after injection of smaller inocula, resulting in phenotypic tolerance and decreased therapeutic efficacy even when treatment was started as early as $12 \mathrm{~h}$ after infection. Therefore, it is crucial to precisely define both the size of bacterial inoculum and the timing of therapy onset in order to obtain reproducible results in experimental models of infection

In conclusion, the good efficacy of amoxicillin/clavulanate treatment against experimental endocarditis due to MRSE, associated with its previously reported success against MRSA infections [11, 12], suggests that this $\beta$-lactam combination might be used in clinical trials to treat patients with MRSE infections. In addition, our observations highlight the importance of phenotypic tolerance in vivo. The rapid slowdown of in situ bacterial growth rates observed between $10^{7}$ and $10^{8} \mathrm{cfu} / \mathrm{g}$ of tissue makes it difficult to merely rely on bacterial densities in the vegetations to ensure reproducible results. It is crucial to precisely define the experimental conditions in animal models of infections, as slight variations in the size of bacterial inoculum or in the timing of therapy may dramatically alter the nature of the experimental results, without influencing the most commonly tested parameter in experimental endocarditis, the bacterial densities in the cardiac vegetations.

\section{Acknowledgments}

We thank Marlyse Giddey and Jacques Vouillamoz for excellent technical assistance.

\section{References}

1. Abraham EP. Introduction. In: Morin RB, Gorman M, eds. Chemistry and biology of beta-lactam antibiotics. Vol 1. New York: Academic Press 1982:21-38.

2. Hewitt JH, Coe WA, Parker MT. The detection of methicillin resistance in Staphllococcus atrets. J Med Microbiol 1969:2:443-56.
3. Brown DFJ, Reynolds PE. Intrinsic resistance to beta-lactam antibiotics in Staphylococcus aureus. FEBS Lett 1980;122:275-8.

4. Hartman BJ, Tomasz A. Low-affinity penicillin-binding protein associated with $\beta$-lactam resistance in Staphylococcus aureus. J Bacteriol 1984;158:513-6.

5. Brumfitt W, Hamilton-Miller J. Methicillin-resistant Siaphylococcus aureus. N Engl J Med 1989;320:1188-96.

6. Izard NC, Hachler H, Grehn M, Kayser FH. Ribotyping of coagulasenegative staphylococci with special emphasis on intraspecific typing of Staphylococcus epidermidis. J Clin Microbiol 1992;30:817-23.

7. Lugeon C, Blanc D, Wenger A, Francioli P. Molecular epidemiology of methicillin-resistant Staphylococcus aureus (MRSA) over a 4-year period in a tertiary university hospital [abstract 1073]. In: Program and abstracts of the 6th European Congress of Clinical Microbiology and Infectious Diseases, Seville, Spain, 1993.

8. Panlilio AL, Culver DH, Gaynes RP, et al. Methicillin-resistant Staphylococcus aureus in U.S. hospitals, 1975-1991. Infect Control Hosp Epidemiol 1992;13:582-6.

9. Martin MA, Pfaller MA, Wenzel RP. Coagulase-negative staphylococcal bacteremia. Ann Intern Med 1989;1 10:9-16.

10. Noble WC, Virani Z, Cree RGA. Co-transfer of vancomycin and other resistance genes from Enterococcus faecalis NCTC 12201 to Sraphylococcus aureus. FEMS Microbiol Lett 1992;93:195-8.

11. Cantoni L. Wenger A, Glauser MP, Bille J. Comparative efficacy of amoxicillin-clavulanate, cloxacillin, and vancomycin against methicillin-sensitive and methicillin-resistant Staphylococcus aureus. J Infect Dis 1989;159:989-93.

12. Franciolli M, Bille J, Glauser MP, Moreillon P. $\beta$-lactam resistance mechanisms of methicillin-resistant Staphylococcus aureus. J Infect Dis 1991;163:514-23.

13. Chambers HF. Coagulase-negative staphylococci resistant to $\beta$-lactam antibiotics in vivo produce penicillin-binding protein $2 \mathrm{a}$. Antimicrob Agents Chemother 1987;31:1919-24.

14. Pierre JR, Williamson R, Bornet M, Gutmann L. Presence of an additional penicillin-binding protein in methicillin-resistant Staphylococ cus epidermidis. S. haemolvticus, S. hominis, and S. simulans with low affinity for methicillin, cephalothin, and cefamandole. Antimicrob Agents Chemother 1990;34:169l-4.

15. Olsson-Liljequist B, Larsson P, Ringertz S, Löfdahl S. Use of a DNA hybridization method to verify results of screening for methicillin resistance in staphylococci. Eur J Clin Microbiol Infect Dis 1993:12:527-33.

16. Tomasz A, Nachmann S, Leaf $\mathrm{H}$. Stable classes of phenotypic expression in methicillin-resistant clinical isolates of staphylococci. Antimicrob Agents Chemother 1991;35:124-9.

17. Goldman PL, Petersdorf RG. Importance of $\beta$-lactamase inactivation in the treatment of experimental endocarditis caused by Staphylococcus aureus. J Infect Dis 1980;141:331-7.

18. Pfaller M, Davenport D, Bale M, Barrett M, Koontz F. Massanari RM Development of the quantitative micro-test for slime production by coagulase-negative staphylococci. Eur J Clin Microbiol Infect Dis $1988 ; 7: 30-3$

19. National Committee for Clinical Laboratory Standards. Approved standard M2-A4. Performance standards for antimicrobial disk susceptibility test. 4th ed. Villanova, PA: NCCLS. 1990.

20. Sahm DF, Washington JA. Antibacterial susceptibility test: dilution methods. In: Balows A, Hausler WJ, Herrmann KL. Isemberg HD. Shadomy HJ, eds. Manual of clinical microbiology. 5 th ed. Washington. DC: American Society for Microbiology, 1991:1 109-16.

21. Thornsberry C, McDougal LK, Gavan TL. Successful use of microdilution in susceptibility tests for methicillin-resistant (heteroresistant) staphylococei. J Gen Microbiol 1983;18:1084-91.

22. Heraief E. Glauser MP. Freedman LR. Natural history of aortic-valve endocarditis in rats. Infect Immun 1982:37:127-31.

23. Chapin-Robertson $\mathrm{K}$, Edberg SC. Measurement of antibiotics in hu- 
man body fluids: techniques and significance. In: Lorian V. ed. Antibiotics in laboratory medicine. 3rd ed. Baltimore: Williams \& Wilkins. 1991:295-366.

24. Frank U, Schmidt-Eisenlorh E, Schlosser V, Spillner G, Schindler M. Daschner FD. Concentrations of flucloxacillin in heart valves and subcutaneous and muscle tissues of patients undergoing open-heart surgery. Antimicrob Agents Chemother 1988:32:930-1.

25. Staniforth DH, Jackson D, Norton R, Davies B. Parenteral augmentin: pharmacokinetics. Int J Clin Pharmacol Ther Toxicol 1984:22:4304.

26. Blouin RA, Bauer LA, Miller DD, Record KE, Griffen WO. Vancomycin pharmacokinetics in normal and morbidly obese subjects. Antimicrob Agents Chemother 1982;21:575-80.

27. Moreillon P, Francioli P, Overholser D, Meylan P, Glauser MP. Mechanisms of successful amoxicillin prophylaxis of experimental endocarditis due to Streptococcus intermedius. J Infect Dis 1986;5:801-7.

28. Durack DT. Beeson PB. Experimental bacterial endocarditis. I. Colonization of a sterile vegetation. Br J Exp Pathol 1972;53:44-9.

29. Berney P, Francioli P. Successful prophylaxis of experimental strepto- coccal endocarditis with single-dose amoxicillin administered after bacterial challenge. J Infect Dis 1990;161:281-5.

30. Rosdahl VT. Jarløv JO. Knudsen AM. Beta-lactamase production in coagulase-negative micrococcaceae. Acta Pathol Microbiol Immunol Scand [B] 1986;94:423-7.

31. Tuomanen E. Phenotypic tolerance: the search for $\beta$-lactam antibiotics that kill nongrowing bacteria. Rev Infect Dis 1986;8(suppl 8):27991.

32. Wood WB, Smith MR. An experimental analysis of the curative action of penicillin in acute bacterial infections. I. The relationship of bacterial growth rates to the antimicrobial effect of penicillin. J Exp Med 1956;103:487-97.

33. Cantoni L, Glauser MP, Bille J. Comparative efficacy of daptomycin, vancomycin, and cloxacillin for the treatment of Siaphylococcus aureus endocarditis in rats and role of test conditions in this determination. Antimicrob Agents Chemother 1990;34:2348-53.

34. Catheral EJ, Irwing R, Mizen LW. Efficacy of amoxicillin/clavulanic acid in experimental Staphylococcus aureus endocarditis in rats. J Antimicrob Chemother 1991;27:117-26. 